\title{
Spinal stabilization for patients with metastatic lesions of the spine using a titanium spacer
}

\author{
Hans Hertlein, Thomas Mittlmeier, Stefan Piltz, Matthias Schürmann, Thomas Kauschke, and Günter Lob \\ Unfallchirurgie, Chirurgische Klinik und Poliklinik der Universität München, Klinikum Großhadern, Marchioninistrasse 15, \\ W-8000 München 70, Federal Republic of Germany
}

\section{Stabilisation rachidienne utilisant un "spacer" en titane chez les patients porteurs de lésions métastatiques de la colonne vertébrale}

Résumé. La décompression antérieure a été réalisée chez 41 patients porteurs de métastases du corps vertébral. Les complications neurologiques étaient patentes chez 36 patients et latentes chez 5 d'entre eux. On a utilisé pour la reconstruction un cylindre de titane, mis en place après la corporectomie et renforcé par une plaque antérieure. L'implant en titane peut être facilement adapté à la longueur nécessaire sans nécessiter de matériel supplémentaire et onéreux. L'implant est rempli de PMMA avant sa mise en place, ce qui facilite la transfixation nécessaire au verrouillage de la rotation. La mortalité à 30 jours est de $9.7 \%$. La douleur a disparu dans 38 cas sur $41(92.7 \%)$, l'amélioration motrice a été manifeste dans 31 cas sur $35(88.6 \%), 6$ patients ne présentaient aucun symptôme neurologique ni avant ni après l'opération. Une dégradation neurologique n'a été relevée que dans 1 cas $(2.4 \%)$. L'efficacité du geste chirurgical a été maintenue jusqu'au décès des patients. Bien que la récidive tumorale à un autre niveau rachidien ait conduit à une chirurgie itérative chez 5 patients, aucun déplacement d'implant n'est survenu durant la période d'observation (recul maximum 44 mois), cela témoignant du caractère mécaniquement faible et sûr du procédé utilisé.

Mots-clés: Métastase rachdienne - Décompression antérieure - Prothèse vertébrale - Déplacement d'implant

Summary. Anterior decompression in spinal metastases of the corporal type with impending $(n=5)$ or present $(n=36)$ neurological complications was performed in 41 patients. For reconstruction, a titanium cylinder was inserted after spondylectomy and augmented with an anterior plate. The titanium implant can easily be adjusted to the length needed without necessitating expensive additional equipment. Outside the patient the implant is filled with polymethylmetacrylate, facilitating plate transfixation for rotational locking. There was a 30-day mortality of $9.7 \%$. Pain relief was apparent in 38 of 41 patients $(92.7 \%)$, and motor improvement was manifest

Correspondence to: H. Hertlein in 31 of 35 cases $(88.6 \%)$. Six patients did not present with any neurological symptoms pre- or postoperatively. Neurological deterioration was registered in only 1 case $(2.4 \%)$. Surgical efficacy was maintained until the death of the patients. Though tumor recurrence at a different spinal level led to consecutive surgery in 5 patients, no implant dislocation occurred during the observation period (maximum 44 months), characterizing the procedure as a mechanically reliable and safe technique.

Key words: Metastatic spinal tumor - Anterior decompression - Prosthetic replacement - Implant dislocation

Due to improved oncological care and increased survival rate of many malignant tumors, the surgeon is confronted with a rising number of metastases of the spine $[12,15]$ tending to cause instability, deformity, pathological fracture, or a neurological deficit with progress of the metastatic growth $[11,15-17]$. According to the metastatic spread via the vertebral venous plexus [1], involvement of the vertebral body represents the major region of metastatic manifestation of the spine $(70 \%-80 \%)$ [11], while the posterior spinal elements or pericordal metastases make up only a minor part of metastatic tumor occurrence (up to $20 \%$ ) $[3,23]$.

Therefore, lesions of the spine should be treated at the main location of tumor invasion, i.e., anterior processes from an anterior approach [5, 26, 27], dorsal manifestations form a posterior [2]. An exclusive posterior decompression formerly advocated for easier accessibility [8] rarely provided effective decompression for anteriorly located tumors $[10,15,21,24,32]$ and generally increased the spinal instability or neurological deficits even after a transient postoperative improvement $[2,5$, $15,31]$.

An anterior approach allows for an effective cord decompression and a rigid internal stabilization, which may be supplemented by a posterior approach if necessary in extended lesions [27]. Bone grafts [25], acrylic cement alone $[10]$ or in combination with a metal fixation device $[10,16]$, bioceramic [19], polymeric [4], or metal spacers $[7,19]$, or special implants $[4,5,20,30,31]$ have been proposed or clinically applied after spondylectomy. 
Since the life expectancy of patients with metastatic spinal disease is rather limited, any procedure requiring a prolonged period of immobilization should not be tried. The technique employed should allow a maximum degree of decompression with an immediate maximum stability, rendering postoperative mobilization of the patients possible without bracing [11].

On the other hand, instability or postoperative dislocation of the implant represents the major risks after spondylectomy and anterior stabilization $(2 \%-10 \%)[5$, $11,17,26,28,29]$.

The purpose of the present study was to examine whether (a) implantation of a latticed titanium cylinder providing a wide contact area with the neighboring vertebrae and a good interlock with the neighboring vertebral ground plates additionally fixed with a standard fixation device (3.5-mm ASIF-DCP (dynamic compression plate) or Zielke device) represented a safe and reproducible technique adequate for most spinal levels and (b) whether the technique could significantly reduce the risk of implant dislocation.

\section{Material and methods}

From January 1, 1988, to August 31, 1991, we operated on 60 patients with metastatic disease of the spinal column. According to the main site of tumor manifestation, a titanium spacer was implanted after anterior spondylectomy in 41 patients who will be discussed in detail. Of these, 23 patients were female, 18 were male. The diagnosis of the primary tumor is shown in Table 1 . The average age at surgery was 57.2 years (range $36-76$ years). With renal carcinoma, angiography was routinely performed preoperatively for major bleeding risks. Intraarterial embolization, however, was only applied in 2 cases. In 31 patients, a single anterior approach was adequate for tumor resection and stabilization, while in 10 patients an anteroposterior approach was necessary. The indications for surgical intervention were analogous to those given in the current literature $[15,23]$ : pain caused by an unstable spine or an impending or manifest pathological spinal fracture or a neurological deficit. Since 35 patients already had neurological symptoms, the surgical treatment was performed as an emergency procedure. None of the patients, however, suffered from a complete paraplegia prior to surgical therapy (compare Table 2). In $17 \mathrm{pa}$ tients, the neurological deficit was the primary manifestation of vertebral metastatic disease. No specific clinical neurological symptoms could usually be attributed to the level of tumor invasion, i.e., the extent of sensible or motoric deficits was only related to

Table 1. Origin of metastasis

\begin{tabular}{lc}
\hline & Number of patients \\
\hline Breast & 13 \\
Lymphoma & 6 \\
Renal & 5 \\
Gastrointestinal & 2 \\
Lung & 3 \\
Prostate & 3 \\
Thyroid gland & 1 \\
Melanoma & 1 \\
Chondrosarcoma & 1 \\
Unknown & 6 \\
Total & 41 \\
\hline
\end{tabular}

Table 2. Preoperative neurological status evaluated according to Frankel et al. [6]

\begin{tabular}{lc}
\hline Frankel grade & Number of patients \\
\hline A & 0 \\
B & 3 \\
C & 18 \\
D & 14 \\
E & 6 \\
\hline
\end{tabular}

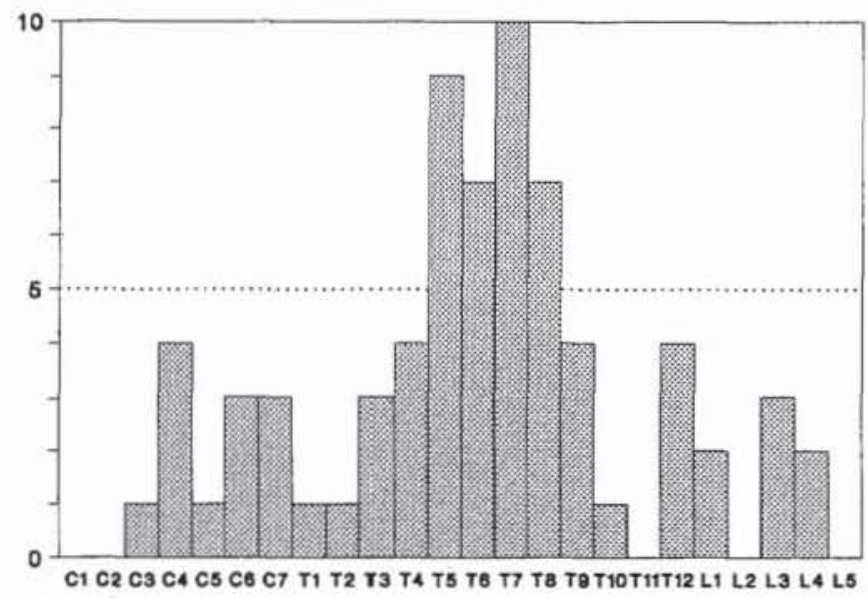

Fig.1. Vertebral levels involved in anterior decompression and prosthetic replacement

the respective spinal level. The distribution of the spinal levels resected are depicted in Fig. 1. In 13 patients, a single vertebra was resected and stabilized, in 27 patients 2 neighboring vertebrae were resected, and in 1 patient a cervical and a thoracic vertebra were resected and stabilized simultaneously.

Surgical technique. In general, a titanium spacer can be used as an universal implant for vertebral body replacement except for the first two cervical levels [9]. The implant has a cylindrical (cervical spine) or oval (thoracic or lumbar spine) cross section and is available in 4 different sizes: $16-\mathrm{mm}$ cylindrical, $17 \times 22 \mathrm{~mm}, 22 \times 28 \mathrm{~mm}$, $26 \times 33 \mathrm{~mm}$ oval (Fig. 2). The length of the implant (standard length varying from 30 to $90 \mathrm{~mm}$ ) may be tailored with a pair of nippers according to the actual length needed intraoperatively. Additionally, the implant may be reinforced at its base and top with a titanium ring fixed with screws to the inner circumference of the cylinder (Fig. 2). Static compressive loading of a standard cylinder yielded a compressive strength of 4000 (cervical spine implant) $-7500 \mathrm{~N}$ (lumbar spine implant) [9]. During cyclic loading, after a million load cycles no permanent mechanical deterioration of the implant could be observed [9]. Beyond that, the cylinder may be filled with bone material or methylmetacrylate outside the patient for increasing the contact areas and easier transfixation of the plate screws. The latter procedure was practised in all 41 patients.

In the cervical spine (including the $T 1$ vertebra), a conventional anterior approach was employed. Spondylectomy was performed including the corresponding discs and the posterior longitudinal ligament until the dura was free from any compromising tumor masses. For easier handling, a distractor was fixed to the neighboring vertebrae anteriorly. After selection of an adequate titanium cylinder, trimming the implant to the correct length, and filling the implant with polymethylmetacrylate (PMMA) on the preparation table, the implant was inserted and protected against dislocation with an H-shaped Orosco plate (Fig. 3). A transfixation of the cylinder by the screws of the plate is not mandatory in the cervical spine. 

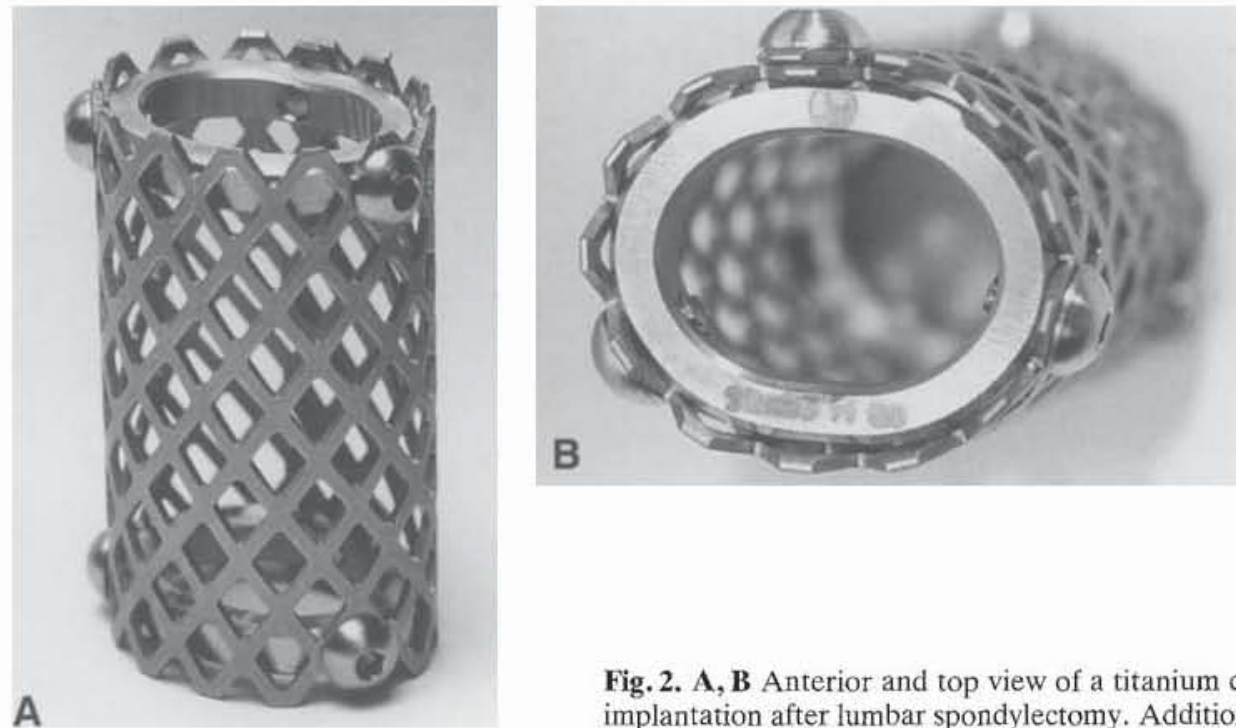

Fig. 2. A, B Anterior and top view of a titanium cylinder (size 4: $22 \times 28 \times 50 \mathrm{~mm}$ ) used for implantation after lumbar spondylectomy. Additional reinforcement is provided by a titanium ring on top and at the base of the cylinder
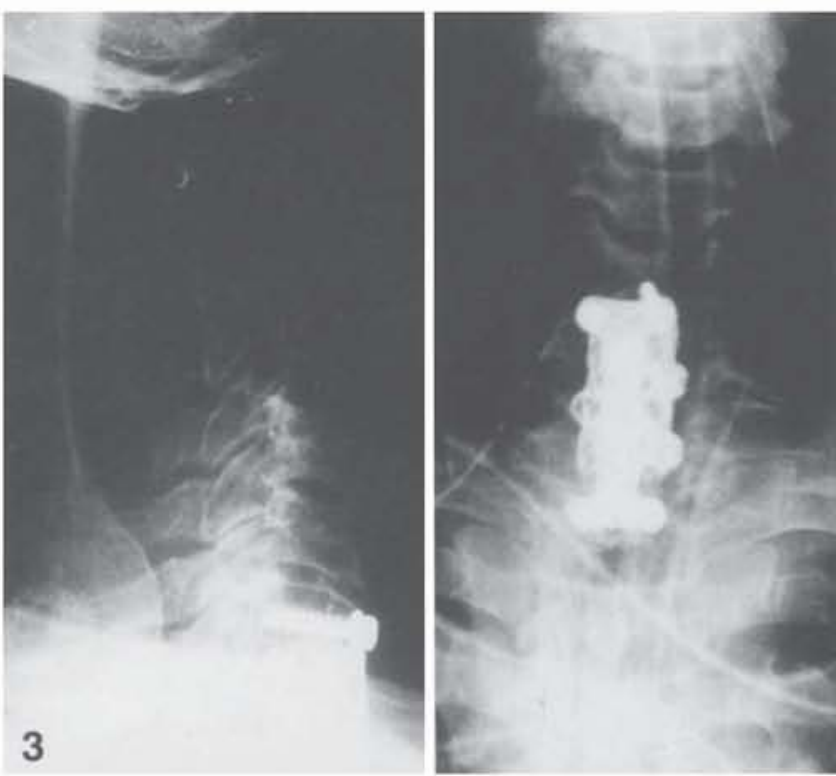

Fig. 3. Anterior replacement of $\mathrm{C} 7$ and $\mathrm{T} 1$ vertebrae by a titanium cylinder. Protection against dislocation is provided by an anterior Orosco plate which does not transfix the implant

In the thoracic vertebral column (T2-11), generally a right posterolateral thoracotomy was performed. Decompression was done in analogy to the cervical spine. After insertion of the implant under hyperlordosis between the vertebral end-plates of the neighboring vertebrae, a $3.5-\mathrm{mm}$ ASIF-DCP was applied laterally, transfixing the titanium spacer/PMMA compound with 2 screws to prevent a lateral tilt or rotation of the implant (Fig. 4). In case of tumor expansion to the posterior spinal elements, an additional posterior approach decompression involving laminectomy and dorsal stabilization was carried out (VDS-Zielke system or intern fixateur or Roy-Camille plates; Fig. 5). For T12 and L1 vertebrae, a thoracoabdominal approach was necessary. In the lumbar vertebrae, usually a left retroperitoneal approach was chosen. In patients with extensive tumor invasion of the anterior and posterior column and consequent manifest or impending instability, a combined anteroposterior approach was necessary. In 3 selected cases

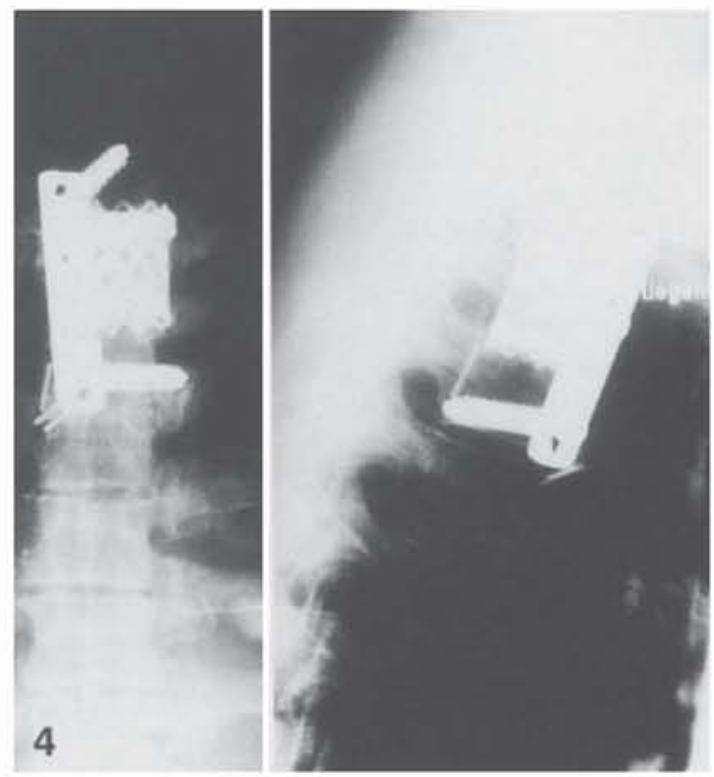

Fig. 4. Replacement of the third thoracic vertebra by a titanium cylinder filled with polymethylmetacrylate (PMMA). Additional anterolateral placement of a $3.5-\mathrm{mm}$ DCP which transfixes the spacer/PMMA compound with 2 screws to prevent rotation of the cylinder

in the lumbar spine, a novel technique was employed, the anterior transpedicular fixation (Fig. 6). With this technique, an additional posterior approach is unnecessary to gain an equivalent stability to combined approach and bilateral stabilization [13]. To protect the retroperitoneal structures, an implant with a smooth surface was chosen and covered with a polyglactin-910-net. Prior to clinical application, an anatomical study revealed that a safe anterior placement of the pedicle screws was possible [13].

Postoperative care. Depending on the neurological status, all patients were mobilized immediately postoperatively. Only in the case of a cervical vertebral body replacement was a soft collar worn for 2 weeks after surgery. Radiation therapy was generally performed postoperatively provided that success was to be expected from the tumor histology result. 

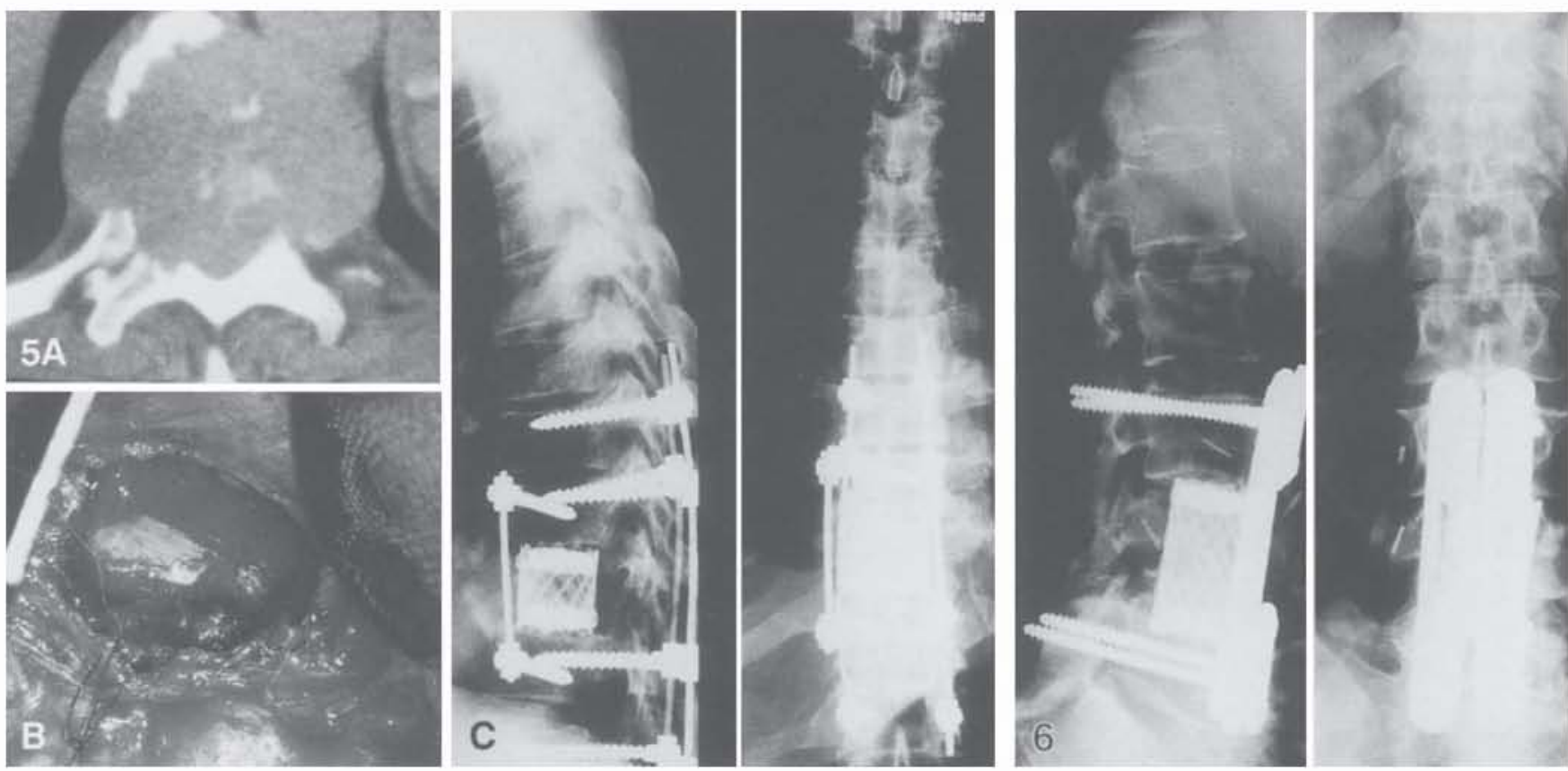

Fig. 5. A Tumorous invasion of a breast cancer metastasis of the complete anterior elements and pedicles of the T9 vertebra. B Intraoperative situs after anterior spondylectomy via a right posterolateral thoracotomy. The dura is completely dissected free from tumorous masses. C Replacement by a titanium cylinder and a Zielke device anteriorly after anterior spondylectomy. Posterior transpedicular fixation with a bilateral Zielke device for major posterior instability due to posterior tumor invasion

Fig. 6. Replacement of the L4 vertebra after anterior spondylectomy. Anterior placement of a rotationally stable compression plate fixateur. No transfixation of the spacer is needed due to the plate position

Postoperative check-up. All patients were evaluated neurologically according to the Frankel score immediately pre- and postoperatively [6]. Follow-up with evaluation of subjective (pain, ambulatory function) and objective criteria was performed until the patient's death $(n=30)$ in 3-month intervals or until the end of the observation period (maximum 44 months) by an independent observer (T.K.) who was not involved in the routine clinical care and surgical procedures.

\section{Results}

No major intraoperative complications were observed. The mean intraoperative blood loss came to $1250 \mathrm{ml}$ (range 200-9000 ml). Postoperatively, 2 lethal complications (1 pneumonia, 1 pulmonary embolism) occurred during the hospital stay of the patients (9th and 10th day after surgery, respectively). Two further patients died during the 30 -day period after the operation due to reasons not related to the surgery (apoplexia, cardiac failure). Two deep infections were registered which could be treated without removal or replacement of the implant and healed without further problems. No implant dislocation was observed; only in 1 case was a slight protrusion of the implant into the cranial end-plate of the neighboring vertebra seen which did not increase up to the death of the patient after 5 months and did not require intervention.

Further surgical therapy was necessary due to tumor recurrence or progression in a neighboring vertebra or at a distant location of the spine in 5 patients during the observation period.

At the same spinal level, no significant tumor recurrence was observed that made surgical intervention necessary.

Significant pain relief was observed in 38 of 41 patients $(92.7 \%)$.

A deterioration of the neurological status after surgery was noted in only 1 patient with expansive invasion of the anterior and posterior elements of the T9 vertebra and a large paraspinal tumor 3 days after surgery

Table 3. Neurological result evaluated by the classification by Frankel et al. [6]

\begin{tabular}{llll}
\hline & $\begin{array}{l}\text { Pre-/post- } \\
\text { operatively }\end{array}$ & $\begin{array}{l}\text { Number } \\
\text { of patients }\end{array}$ & $\begin{array}{l}\text { Spinal } \\
\text { level }\end{array}$ \\
\hline Deterioration & C-A & 1 & $1 \mathrm{t}$ \\
No change & B-B & 2 & $1 \mathrm{c}, 1 \mathrm{l}$ \\
& $\mathrm{C}-\mathrm{C}$ & 1 & $1 \mathrm{c}$ \\
& $\mathrm{E}-\mathrm{E}$ & 6 & $2 \mathrm{c}, 3 \mathrm{t}, 11$ \\
Improvement & & & \\
1 grade & $\mathrm{B}-\mathrm{C}$ & 1 & $1 \mathrm{t}$ \\
& $\mathrm{C}-\mathrm{D}$ & 8 & $1 \mathrm{c}, 5 \mathrm{t}, 21$ \\
& $\mathrm{D}-\mathrm{E}$ & 14 & $1 \mathrm{c}, 9 \mathrm{t}, 41$ \\
2 grades & $\mathrm{C}-\mathrm{E}$ & 8 & $2 \mathrm{c}, 5 \mathrm{t}, 11$ \\
\hline
\end{tabular}

$n=41$ patients; 6 patients had no neurological deficit before operation

Spinal levels: $\mathrm{c}=\mathrm{C} 3-\mathrm{T} 1 ; \mathrm{t}=\mathrm{T} 2-\mathrm{T} 11 ; \mathrm{I}=\mathrm{T} 12-\mathrm{L} 5$ 
due to excessive bleeding and epidural hematoma formation. Immediate decompression after manifestation did not lead to neurological recovery. A neurological improvement by one or two Frankel grades was seen in 31/ $35(88.6 \%)$ patients (Table 3$)$.

The mean survival rate of all patients after surgery was 8.5 months due to the advanced stage of the malignant disease in this patient group.

\section{Discussion}

Secondary neoplastic disease represents the major type of tumorous lesion of the spine [22, 23]. Frequency, biological behavior, and prognosis essentially depend on the type of the primary tumor $[15,18]$. As such, metastatic spinal disease does not represent a homogeneous problem. Due to the improvement of chemo- and radiotherapy with a concomitant increase of life expectancy of patients with malignant diseases, the number of patients developing vertebral metastases with corresponding sequelae has increased and will continue to do so $[12,15]$.

In contrast to the therapy of benign lesions of the spine, surgical treatment of vertebral metastases generally cannot claim a curative aim [2]. The survival time does not essentially depend on the therapeutic approach towards the spinal metastasis $[17,24]$. Thus, the indications for surgical intervention are mainly palliative, such as the relief of otherwise intractable pain and the elimination or improvement of neurological symptoms in the presence of pathological spinal fracture deformity or cord compression $[15,23]$. Therefore, the main goal is improvement of the quality of life [23], thereby influencing indirectly the life expectancy by avoiding confinement to a wheelchair or to bed with the ensuing typical complications.

Historically, the mere dorsal decompression of a mostly anterior tumor manifestation (up to $80 \%$ ) has often yielded unsatisfying postoperative results due to inadequate accessibility of the main tumor masses anteriorly or due to added spinal instability with removal of the posterior vertebral elements $[2,10,15,21,24,31,32]$.

During the past decade, a multitude of surgical procedures has been published propagating an anterior or a combined anterior and posterior approach with resection of the involved structures and a stabilization that should be as rigid as possible $[4,5,7,9-12,15-20,24-$ 31]. The approach is determined by the main site of tumor localization. In our series, in 10 patients (24\%) a bilateral approach was regarded as necessary. The frequency of a bilateral approach is quite variable in the literature, and the criteria for an absolute indication are apparently a matter of discussion $[14,16]$.

Since autologous bone grafts alone require several months for incorporation to achieve adequate stability [10] without external bracing or immobilization, and this can be delayed if irradiation is applied, most authors have combined the technique of acrylic bone cement insertion after spondylectomy with augmentation by a metal implant [5, 11, 26-28]. Apparently, the percentages of neurological improvement, neurological worsening, morbidity, and 30-day mortality are comparable irrespective of the specific technique used for additional stabilization (Table 4) $[5,11,17,26,28,29]$. On the other hand, the technique of in situ hardening of the PMMA has its particular risks $[5,10,20]$ and does not represent a standardized technique with reproducible and reliable biomechanical properties: Thus, the number of secondary implant dislocations is relatively high ( $2 \%-10 \%$; Table 4$)$.

In those studies in which an alloplastic implant had been used after spondylectomy, no implant dislocation or only a rather reduced rate of implant motion - mostly due to technical errors at implantation - was observed $[5,19,20,30,31]$. On the other hand, most spinal prostheses require substantial additional instrumentation or intraoperative effort to fit the implant into the gap after excision of the metastasis $[4,5,19,20,30,31]$. This is not true with the titanium spacer exclusively used in the present series. From 4 different standard sizes, the individual prosthetic length can be adjusted intraoperatively just by using a pair of nippers [9].

No implant dislocation was observed in our series. A slight intrusion into the end-plate of the neighboring superior vertebra was self-limiting and did not require surgical intervention. This may be attributed to the excellent anchoring properties of the sawtooth-like surface of the titanium spacer protected from rotation by the 3.5-mm ASIF-DCP. The clinical results - subjective and objective - are comparable with those reported for other procedures using the anterior approach (Table 4) $[5,11,12,16,17,26-29]$. Recurrence of the tumor led to
Table 4. Comparison of results after vertebral body resection and stabilization by anterior approach

\begin{tabular}{lccllll}
\hline Reference & $\begin{array}{l}\text { Number } \\
\text { with an- } \\
\text { terior } \\
\text { approach }\end{array}$ & $\begin{array}{l}30 \text {-day } \\
\text { mortal- } \\
\text { ity (\%) }\end{array}$ & $\begin{array}{l}\text { Major } \\
\text { morbid- } \\
\text { ity (\%) }\end{array}$ & $\begin{array}{l}\text { Internal } \\
\text { fixation } \\
\text { failure } \\
(\%)\end{array}$ & $\begin{array}{l}\text { Neuro- } \\
\text { logic } \\
\text { worsen- } \\
\text { ing (\%) }\end{array}$ & $\begin{array}{l}\text { Motor } \\
\text { improve- }\end{array}$ \\
\hline Harrington [11] & 52 & 8 & 12 & 10 & 2 & 78 \\
Siegal and Siegal [26] & 47 & 6 & 17 & 7 & 2 & 79 \\
Sundaresan et al. [28] & 101 & 8 & 10 & 9 & 0 & 69 \\
Fidler [5] & 17 & 18 & NS & 6 & 0 & 93 \\
O'Neil et al. [17] & 33 & NS & 15 & 6 & 3 & 68 \\
Turner et al. [29] & 41 & 10 & 12 & 2 & 0 & 89 \\
This series & 41 & 10 & 5 & 0 & 2 & 86 \\
\hline
\end{tabular}

NS $=$ not stated 
reintervention in 5 of 41 cases during the observation period, but never at the same spinal level. In no case was an implant removal necessary, and no neurological deterioration had to be registered after repeated surgery. Obviously, a nonextensive tumor excision may predetermine a massive local and clinically relevant tumor recurrence despite the limited life expectancy of the patients. Thus, a number of instabilities reported after surgery by others (compare Table 4) may be attributed to a limited tumor excision at primary surgery.

In our series, the number of multiple level spondylectomies was relatively high in comparison with others [10, 17]. As no local tumor recurrence occurred at the same spinal level, this procedure of radical tumor excision at primary surgery is supported by the results, independent of the specific implant employed.

Apparently, the use of a titanium spacer with this geometry represents a practicable and safe procedure after anterior spondylectomy. Eventual thermal damage due to in vivo polymerization of the PMMA [10] is eliminated. The PMMA used for filling the titanium cylinder only serves as a support for the DCP screws and is not necessary for implementation of the mechanical stability. The biomechanical properties and the design of the titanium spacer, as demonstrated in vitro [9], guarantee a minimum risk of dislocation after implantation, providing an optimum maintenance of stability and the neurological status achieved after anterior spinal cord decompression.

\section{References}

1. Boland PJ, Lane JM, Sundaresan N (1982) Metastatic disease of the spine. Clin Orthop 169:95-102

2. Bridwell KH, Jenny AB, Saul T, Rich KM, Grubb RL (1988) Posterior segmental spinal instrumentation (PSSI) with posterolateral decompression and debulking for metastatic thoracic and lumbar spine disease. Spine 13:1383-1394

3. Brihaye J, Ectors P, Lemort M, Van Houtte P (1988) The management of spinal epidural metastases. Adv Techn Stand Neurosurg 16:121-176

4. Burri C, Claes L, Mutschler W, Wörsdörfer O (1989) Kohlenstoffaser-verstärkte Polysulfon-Implantate für die Tumorchirurgie an der Wirbelsäule. Akt Traumatol 19:297-301

5. Fidler MW (1986) Anterior decompression and stabilisation of metastatic spinal fractures. J Bone Joint Surg $[\mathrm{Br}]$ 68:83-90

6. Frankel HL, Hancock DO. Hyslop G, Melzak J, Michaelis LS, Ungar DH, Vernon JDS, Walsh JJ (1969) The value of postural reduction in the initial management of closed injuries of the spine with paraplegia and tetraplegia. Paraplegia 7:179-192

7. Griss P (1987) Osteosynthesen und Wirbelkörperersatz bei Wirbelsäulentumoren. Orthopäde 16:415-421

8. Hall AJ, MacKay NNS (1973) The results of laminectomy for compression of the cord or cauda equina by extradural malignant tumour. J Bone Joint Surg 55-B, 497-505

9. Harms J, Stoltze D, Biedermann L (1990) Wirbelkörperersatz, -platzhalter. Oral presentation, workshop on correction and stabilization of spinal diseases with the Moss-system, Bad Nauheim, FRG, 29 June 1990

10. Harrington KD (1981) The use of methylmethacrylate for vertebral-body replacement and anterior stabilization of pathological fracture-dislocations of the spine due to metastatic malignant disease. J Bone Joint Surg [Am] 63:36-46
11. Harrington KD (1984) Anterior cord decompression and spinal stabilization for patients with metastatic lesions of the spine. J Neurosurg 61:107-117

12. Harrington KD (1988) Anterior decompression and stabilization of the spine as a treatment for vertebral collapse and spinal cord compression from metastatic malignancy. Clin Orthop 223:177-197

13. Hertlein H, Mittlmeier T, Schürmann M, Lob G (1992) Anterior transpedicular instrumentation of the lumbar spine: an anatomical study. J Spinal Disord 5 (in press)

14. Johnston FG, Uttley D, Marsh HT (1989) Synchronous vertebral decompression and posterior stabilization in the treatment of spinal malignancy. Neurosurgery 25:872-876

15. Lee CK, Rosa R, Fernand R (1986) Surgical treatment of tumors of the spine. Spine 11:201-208

16. Manabe S, Tateishi A, Abe M, Ohno T (1989) Surgical treatment of metastatic tumors of the spine. Spine 14:41-47

17. O'Neil J, Gardner V, Armstrong G (1988) Treatment of tumors of the thoracic and lumbar spinal column. Clin Orthop 227:103-112

18. Onimus M, Schraub S, Bosset JF, Guidet M (1986) Surgical treatment of vertebral metastasis. Spine 11:883-891

19. Ono K, Yonenobu K, Ebara S, Fujiwara K, Yamashita K, Fuji T, Dunn EJ (1988) Prosthetic replacement surgery for cervical spine metastasis. Spine 13:817-822

20. Polster J, Wuisman P, Matthiaß HH, Brinckmann P (1989) Die ventrale Stabilisierung von primären Tumoren und Metastasen der Wirbelsäule mit dem Wirbelkörperimplantat und Palacos. Z Orthop 127: 414-417

21. Roy-Camille R, Saillant G, Lapresle P, Mazel C, Mariambourg G (1985) Traitement chirurgical des métastases du rachis par stabilisation à l'aide de plaques postérieures vissées dans les pédicules vertébraux. Rev Chir Orthop 71:483-492

22. Schaberg J, Gainor BJ (1985) A profile of metastatic carcinoma of the spine. Spine 10:19-20

23. Schwarzenbach O, Boos N, Aebi M (1990) Metastasen und durch Metastasen bedingt pathologische Frakturen der Wirbelsăule. Unfallchirurg 93:457-466

24. Sherk HH, Nolan JP Jr, Mooar PA (1988) Treatment of tumors of the cervical spine. Clin Orthop 233:163-167

25. Shirakusa T, Motonaga R, Yoshimine K, Takada S, Ueda H, Yamasaki S, Takachi T, Yoh S (1989) Anterior rib strut grafting for the treatment of malignant lesions in the thoracic spine. Arch Orthop Trauma Surg 108:268-272

26. Siegal T, Siegal T (1985) Vertebral body resection for epidural compression by malignant tumors. J Bone Joint Surg [Am] 67: 375-382

27. Sundaresan N, Galicich JH (1984) Treatment of spinal metastases by vertebral body resection. Cancer Invest 2:383-397

28. Sundaresan N, Galicich JH, Lane JM, Bains MS, McCormack P (1985) Treatment of neoplastic epidural cord compression by vertebral body resection and stabilization. J Neurosurg 63: 676-684

29. Turner PL, Prince HG, Webb JK, Sokal MPJW (1988) Surgery for malignant extradural tumours of the spine. J Bone Joint Surg [Br] 70:451-456

30. Waisbrod H (1988) Treatment of metastatic disease of the spine with anterior resection and stabilization by means of a new cancellous metal construct. Arch Orthop Trauma Surg 107:222-225

31. Wuisman P, Polster J, Härle A, MatthiaB HH, Brinckmann P (1989) Das Wirbelkörperimplantat als Behandlungsprinzip bei Tumoren und Metastasen der thorakalen und lumbalen Wirbelsăule. Z Orthop $127: 25-31$

32. Young RF, Post EM, King GA (1980) Treatment of spinal epidural metastases. Randomized prospective comparison of laminectomy and radiotherapy. J Neurosurg 53:741-748 